\title{
Does age influence surgical treatment for breast cancer?
}

\author{
M Renne*, R De Vinci, V Diaco, M G Fava, L Roveda, G Vescio, D Voci, U Prati \\ From de Senectute: Age and Health Forum \\ Catanzaro, Italy. 5-7 December 2009
}

\section{Background}

The incidence of primary breast cancer in elderly patients is increasing.

The histotype of cancer isn't different from the younger population; between $20-30 \%$ of older patients have an aggressive biologic phenotype with negative ER and PgR expression; often the TNM stage is more advanced in these patients than in younger ones, mainly owing to the fact that usually mammographic screenings stop at 70 years old. The current study is aimed at evaluating the treatment of choice for elderly women (over 70), mainly concerning whether they are co-morbidities, psychosocial and cultural disparities, and reduced self-rated physical function may play a role in surgical decision making.

\section{Materials and methods}

From September 2006 to October 2009, 57 patients, aged over 70 years, were admitted for breast cancer; 13 patients were over 80 .

$80 \%$ of them had one or more co-morbidities and $30 \%$ of them had three or more co-morbidities.

All the patients received a core biopsy that confirmed invasive cancer, and then underwent surgery; 2 patients received HOT therapy with Aromatase inhibitor before surgery, having obtained a down-staging from T4 to T1c in sixth months of treatment. Three T4 patients are still under neo-adjuvant treatment. The opportunity of immediate reconstruction was always offered to patients candidate to mastectomy. The average follow up time was 15 months.

\section{Results}

On the basis of TNM the patients were thus divided: $54.4 \%$ were early cases; $26.31 \% \mathrm{~T} 2 \mathrm{~N}+\mathrm{M} 0 ; 10.52 \% \mathrm{~T} 3$; $8.77 \% \mathrm{~T} 4$. All of them are still alive and disease free.

\footnotetext{
Oncologic Surgery Unit, Cancer Centre of Excellence "Fond. T.Campanella".
} Catanzaro, Italy
Three patients, who were M1 at diagnosis, died during the follow up (average survival 6 months). In our experience few patients had psychological problems with accepting mastectomy, nevertheless they refused reconstructive surgery. The overall amount of patients who required plastic surgery was low.

\section{Conclusions}

In our experience all the patients received the gold standard treatment despite age and co-morbidities. Nevertheless we think that in patients with depressive diseases, conservative surgery and radiotherapy can be considered as an alternative to a mastectomy.

\section{Published: 19 May 2010}

\section{References}

1. Phuong Tran, lan S Fentiman: Better treatment for breast cancer in older patients. Expert Rev. Anticancer Ther 2009, 9(8):1081-1090.

2. Albrand G, Terret C: Early breast cancer in elderly: assessment and management considerations. Drug Aging. 2008, 25(1):35-45.

3. Tang SW, Parker $\mathrm{H}$, et al: Early primary breast cancer in the elderlyPattern of presentation and treatment. Surg. Oncol. 2009.

doi:10.1186/1471-2318-10-S1-A28

Cite this article as: Renne et al:: Does age influence surgical treatment for breast cancer? BMC Geriatrics 2010 10(Suppl 1):A28.

Submit your next manuscript to BioMed Central and take full advantage of:

- Convenient online submission

- Thorough peer review

- No space constraints or color figure charges

- Immediate publication on acceptance

- Inclusion in PubMed, CAS, Scopus and Google Scholar

- Research which is freely available for redistribution 